\title{
Recentring Peripheral Queerness and Marginal Art in Portrait of a Lady on Fire (2019)
}

\author{
Madeleine Pelling
}

Citation: Pelling, Madeleine. 2021. Recentring Peripheral Queerness and Marginal Art in Portrait of a Lady on Fire (2019). Humanities 10: 73. https://doi.org/10.3390/h10020073

Received: 10 February 2021

Accepted: 28 April 2021

Published: 5 May 2021

Publisher's Note: MDPI stays neutral with regard to jurisdictional claims in published maps and institutional affiliations.

Copyright: (C) 2021 by the author. Licensee MDPI, Basel, Switzerland. This article is an open access article distributed under the terms and conditions of the Creative Commons Attribution (CC BY) license (https:// creativecommons.org/licenses/by/ $4.0 /)$.

\author{
Centre for Eighteenth-Century Studies, University of York, York YO1 7EP, UK; mp656@york.ac.uk
}

\begin{abstract}
This essay examines the ways in which Céline Sciamma's 2019 film Portrait de la Jeune Fille en Feu (Portrait of a Lady on Fire) looks to centralise onscreen homosexual experience through engagement with, and queering of, eighteenth-century art practices and the discourse surrounding them. From its reception of Ovid's Metamorphoses to ideas espoused by the eighteenth-century art critic and philosopher Denis Diderot, Portrait looks to traditionally peripheral spaces, or edgelands, and the visual and embodied consequences of transcending them. Engaging closely with eighteenthcentury processes of artmaking, the film transforms sketches on paper, paint applied to canvas and wood, miniatures held close to the body and erotica annotated in the margins into queer-coded sites used to reflect and document the developing relationship at its heart.
\end{abstract}

Keywords: queer; lesbian; portraiture; film; marginal; Diderot; French cinema; painting; artist; eighteenth century

[...] the truth of nature is forgotten, while the imagination is filled with gestures, postures, and figures that are false, forced, ridiculous and cold. There they're stored away, re-emerging for application to the canvas. Whenever the artist picks up his chalks and brushes, these limp phantoms revive and present themselves to him; they're a perpetual distraction, and he who managed to exorcise them from his head would be a prodigy indeed $^{1}$.

Denis Diderot, Essai sur la peinture, 1765

In the Essai sur la peinture (Notes on Painting), an addendum to his 1765 Salon on the biennial art exhibition at the Louvre, Denis Diderot criticised the traditional training of painters, in which they drew from plaster casts and classical models. Instead, he espoused an approach that relied on careful observance of, and interaction with, live subjects and, with that, consideration of desiring, damaged, aging and feeling flesh. This essay explores the way in which Céline Sciamma's 2019 film Portrait de la Jeune Fille en Feu (Portrait of a Lady on Fire), set in France around the same time as Diderot was writing, examines this relationship between artistic process and embodied experience. ${ }^{2}$ Portraying onscreen the fictional story of artist Marianne's (Noémie Merlant) commission to paint the unwilling bride-to-be Héloïse (Adèle Haenel), Sciamma looks, I argue, to subvert Diderot's presumed male artist and bring into focus a generative dialogue between art and lived, specifically lesbian, experience. In doing so, she asserts the potential of cinema as a productively queer and art historiographical tool, used to tell stories beyond the patriarchal and relatively heteronormative eighteenth-century salon.

Here, I follow Ula Lukszo Klein's application of the term 'lesbian' to cinematic representations of historical romantic and sexual relationships between women. ${ }^{3}$ While, as George Haggerty has cautioned, historians of sexuality must consider and look beyond the relative absence of 'keyhole testimonies' in identifying their pre-1900 subjects as queer,

\footnotetext{
(Diderot 1765).

(Sciamma 2019).

(Klein 2018).
} 
Klein proposes the application of 'lesbian' to highlight, and counter, modern cinema's consistent failure to represent meaningfully onscreen same-sex female desire. ${ }^{4}$ In particular, she notes how Saul Dibb's The Duchess (2008) and Benoît Jacquot's Les Adieux à la Reine (2012) use eroticised homosexual interactions to titillate audiences and underscore characters' 'lack of fulfilment [ ... ] in other realms of their lives'. ${ }^{5}$ This landscape, however, is beginning to change, with a slew of more recent sapphic-centred productions, among them the BBC's ongoing Gentleman Jack (2019-) and Hulu's Harlots (2017-), turning to increasingly experimental forms in order to make visible onscreen a spectrum of sexual desires. Subverting past genre practices and leading this shift towards more diverse drama, in terms of both representation and form, Sciamma queers the visual and textual modes available to, and generated by, film to recentre lesbian desire. While the film's narrative is concerned primarily with the love story at its heart, it looks to locate it within broader (to borrow Jack Halberstam's terms) 'nonnormative logics' of queerness and their 'alternative relations to time and space'. ${ }^{6}$ Portrait's queerness, I suggest, is articulated specifically through the peripheral spaces in which art works are produced and displayed, as well as the queer coding of the materials and processes by which they are made. Marginal, fleeting and experimental spaces of art practice-among them the edges of books, the miniature portrait and the queer-encoded canvas-are recentered within the cinematic frame as the means to make visible experiences routinely absent from both the historical record and the costume drama genre.

Cinema's propensity for exploring perceived peripheral stories through art onscreen has already been attested by Susan Felleman. She suggests; ' $[\mathrm{t}] \mathrm{he}$ "otherness" of the other visual arts has, to cinema, a significant, although rarely simple or directly correlative relationship to the way that other "othernesses" [ . . . ] function in the larger culture and society within which cinema operates'. ${ }^{7}$ For Sciamma, the eighteenth century proved a rich setting for her story. 'I found out there was an amazing moment in art history in the second part of the 18th century, just before the French Revolution', she claimed in an interview with Sight $\mathcal{E}$ Sound magazine, 'when there was a rise of a female artistic scene [ . . . ] I had a real urge to tell their stories when I discovered these women, who had been forgotten'. ${ }^{8}$ Cinema has predominantly prioritised male artists onscreen, favouring Renaissance masters such as Rembrandt, da Vinci, Vermeer and — a notable female exception-Artemisia Gentileschi. ${ }^{9}$ Nineteenth-century artists are similarly well represented, as evidenced in recent film and television portrayals of J. M. W. Turner, the Pre-Raphaelite Brotherhood and the leading Impressionists. The eighteenth century, Steven Jacobs notes, has received comparably little attention from filmmakers interested in portraying onscreen historical or fictional artists. However, where the artist biopic is usually concerned with the '(proto)modern artist as an independent [and exceptional] individual', Portrait looks to the potential of painterly process in this period to present not only its characters but art history itself in feminist and queer terms. ${ }^{10}$ Without an distinct body of work or historical figure to draw on, the film features collagic borrowings and combines elements from a range of eighteenth-, nineteenth- and twentieth-century works to create a coherent painterly aesthetic. The construction of Marianne's artistic style was, much like the film's narrative, a singularly female endeavour in which Sciamma, cinematographer Claire Mathon and contemporary painter Hélène Delmaire conducted extensive research in museum collections in Paris and London. Looking to replicate the work of eighteenth-century portraitists with a degree of authenticity, the trio turned to works by Élisabeth Vigée Le Brun (1755-1842) and

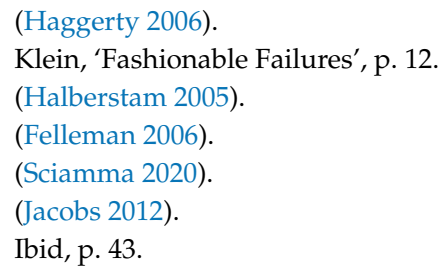


Adélaïde Labille-Guiard (1749-1803), as well as the landscapes of Jean-Baptiste-Camille Corot (1796-1875) and still-life paintings by Jean-Baptiste-Siméon Chardin (1699-1779). ${ }^{11}$

In her work to recover a material culture of eighteenth-century lesbianism, Klein notes that ' $[\mathrm{w}]$ hile intense female friendships were revered and admired' in this period, 'descriptions of sex between women are often rendered in terms of male-gaze erotica or reviled as unnatural'. ${ }^{12}$ Although, as Emma Donoghue has argued, fictions depicting sapphist intercourse, such as Henry Fielding's The Female Husband (1746), 'must have been crucial sources of information about the possibilities of lesbian existence', they were most commonly authored by men and, Klein suggests, geared towards the pleasure of the male reader. ${ }^{13}$ Cinematic reimaginings of this period offer opportunity for revision although, as Klein has set out, the results in centering lesbian desire and inviting a queer gaze have been mixed and often render passions portrayed as disappointingly 'manic, childish, and obsessive', else a mirage 'that can never be discussed or repeated'. ${ }^{14}$

In her foundational essay 'Visual Pleasure and Narrative Cinema', Laura Mulvey identified cinema's inherent scopophilia, 'in which looking itself is a source of pleasure', and its invitation of a 'controlling and curious gaze'. ${ }^{15}$ The identity, or identification, of the looker is, as Amelia Jones has argued, central in how we see, interpret and give value to the visual arts. ${ }^{16}$ For Mulvey, cinema's imagined audience, and therefore the one to which its modes of seeing are coded, has been historically male and heterosexual. Within this system, women are castrated images only, symbolic presences adherent to a cinematic phallocentrism. Beyond Hollywood, however, independent film has regularly found ways to subvert this and make room for alternate ways of both seeing and telling peripheral stories. Rethinking cinema in this way, Patricia MacCormack has proposed, 'can alter the way women have been both denied a specific gaze and defined as gazing masochistically or transvestically, while acknowledging that spectators desire cinema in excess of the meaning of images and their deferral to established sexualities' ${ }^{17}$ In Portrait, Sciamma queers the scopophilic and patriarchal-coded gaze of the cinematic viewer via her treatment of the eighteenth-century artist's vision, its formation and training as well as, eventually, its reversal and reciprocation. In laying out the signifiers and subverting the signified in, simultaneously, eighteenth-century art and modern cinema, Sciamma draws viewers' attention to the construction of images, and the feminist and queer possibilities in deconstructing and reassembling them. In imitating Marianne's ocular oscillation, I suggest, Sciamma directs repeatedly the viewer's gaze between living subject and painted surface, connecting and conflating artistic vision with desirous looking. Artist, actors, filmmaker and audience align in an expansive and technologically dualistic through-view, a way of seeing and being seen highly conscious of the art forms through which it is both expressed and consumed, and in which cinema is positioned as the inheritor, and queerer, of painterly modes of representing.

Sciamma sets out her manifesto in the opening shots of the film, in which a blank sheet of paper fills the screen, apparently boundless, before it is overlayed with the hand of a young girl. Applying the sharpened end of a stick of charcoal to the paper, the disembodied hand begins to make its mark. This sequence is repeated to show similar pieces of blank paper and the hands of various would-be artists before it is revealed the action is taking place inside an art lesson directed by the film's protagonist, Marianne, who sits as a model for her young pupils. Questions of women's creative and sexual autonomy, who is looked at and who seen, and the coded-queer spaces in which this might take place are central here. In defining queer space here, I turn to Aaron Betsky's designation:

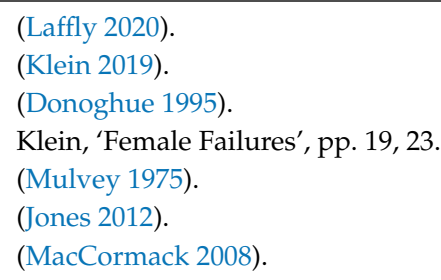


By its very nature, queer space is something that is not built, but implied, and usually invisible. Queer space does not confidently establish a clear, ordered space for itself [ ... ] It is altogether more ambivalent, open, leaky, self-critical or ironic, and ephemeral. queer space often doesn't look like an order you can recognize, and when it does, it seems like an ironic or rhetorical twist on such an order. $^{18}$

For Marianne, the engagement of marginal spaces as a means of self-construction and preservation are deeply rooted in her personal history. As a young girl residing in a convent, she is punished for 'drawing in my notebook's margins'. Throughout Portrait, sketches on paper, paint applied to canvas and wood, miniatures held close to the body and erotica annotated in a copy of Ovid's Metamorphoses exist as, or are transformed into, queer space. They are fleetingly produced, vulnerable to erasure and most often concealed and diminutive. They exist in the space between creation and destruction, freedom and oppression, land and sea, reality and fiction, image and flesh, life and death and are haunted by the inevitability of loss. Terry Castle has suggested that ' $t$ the lesbian remains a kind of "ghost effect" in the cinema world of modern life: elusive, vaporous, difficult to spot-even when she is there, in plain view, mortal and magnificent, at the center of the screen'. ${ }^{19}$ For Sciamma, it is the heteronormative that is ghostly, transformed to the spectral periphery of a film that, instead, prioritises its subjects and the queer modes through which they express themselves. Like the 'limp phantoms' of Diderot's deathly artistic traditionalism, the urban art world from which Marianne steps and the impending marriage faced by Héloïse combine on the edges of Sciamma's frame, a constant presence that threatens, but makes all the richer, the unfolding love story at the film's centre.

The first section of this essay looks to Portrait's engagement with Ovid's story of Orpheus and Eurydice and, with it, the proposed volatility of various thresholds and the consequences of transgressing them. In considering this interpretive framework alongside Marianne's efforts to paint the commissioned portrait of Héloïse, I explore the gender and sexual politics of the artist's gaze and Sciamma's overt reading of both the myth and cinematic traditions of art onscreen in feminist and queer terms. In the second part, I turn to the ways in which Portrait distorts and corrupts this vision, leading to questions of bodily and artistic consent. I propose that, from the use of hallucinogens in summoning the spectral to the uncanny reflectiveness of the mirrored surface, the film explores the boundaries between queer artmaking and female embodied experience to powerful effect.

\section{A Feminist Eurydice, or, a Woman on the Edge}

The first painting to present onscreen in Portrait, despite its relatively brief appearance, is the eponymous work of the film. It depicts a woman walking on a beach, the hem of her dress on fire. This work, brought from the depths of Marianne's studio to the attention of the viewer via her inquisitive young pupils, represents the painful memory of a commission undertaken on an undisclosed Brittany island some years previously. In what follows, this period of the artist's life is recounted from her perspective, in which the island itself becomes an edgeland and where the sea, beach and cliffs form the visual and elemental parameters of the unfolding narrative. ${ }^{20}$ Within this topographically peripheral and spatially limited cinematic world, the crossing of thresholds-whether by accidental slippage, suicidal intent or sexual or artistic awakening - takes on special and particular significance. On travelling to the island by boat, Marianne and the initially blank canvases she brings with her are first forced to pay a toll. When her art materials fall overboard, she dives in after them, immersing herself in the chilly water (a baptismal moment from which both artist and tools emerge onto the land). Shortly after her arrival, Marianne

8 (Betsky 1997).

19 (Castle 1993).

20 For more on the queer cinematic relationship to the sea and beach, see (Berns 2017; Pullen 2018). For an overview of the beach in French cinema as a space of sexual and youthful freedom, see (Handyside 2014). 
learns that the elder sister of her subject, Héloïse, fell from the cliff edge in a likely suicide, marking such margins as not only transportative and transformative, but also potentially deadly. Marianne settles into the quotidian routines and diurnal rhythms in the home of her client, a household devoid of men and occupied only by herself, Héloïse and a servant, Sophie (Luàna Bajrami). Through a series of painterly tableaux in which the women work at the kitchen table, craft and search for plants amongst the dunes, the film makes visible the collapse of hierarchy as their rank and experiences outside of their immediate surroundings fall away. For Betsky, we might read such homosocial and 'sensuous, inwardturned alternatives to both daily life and male domination [as] queer spaces' ${ }^{21}$ Sciamma privileges this narrow world, which is largely without historical or material context. Pared back sets with minimal props, infrequent costume changes and an overarching emptiness, in terms of both the interior and exterior locations in which the action takes place as well as the soundscape that accompanies it, all serve to underscore its liminality.

In rationalising its fixation on the in-between, Portrait turns to the myth of Orpheus and Eurydice, read aloud by Héloïse from Marianne's copy of Ovid's Metamorphoses during a pivotal scene. In the tale, Orpheus bargains with the gods of the underworld to be allowed to lead his deceased love, Eurydice, out of Hades and upwards towards new life. Permission is granted on the condition that Orpheus does not look back at Eurydice until they have crossed the threshold to the living. Focusing on the moment in which Orpheus turns prematurely, thus condemning Eurydice to a second death, the film foregrounds liminal space and fleeting moments between worlds, casting its frame wide to not only include, but centralise, these edges. Orpheus and Eurydice were the regular subjects of paintings throughout the early modern period and, by the eighteenth century, proved a popular subject for plays, such as David Mallet's Eurydice: A Tragedy (1780), and numerous operas. ${ }^{22}$ More recently, Judith Butler has critiqued the work of artist Bracha Lichtenberg Ettinger, whose oil paintings and works on paper focus on mythological female figures such as Medusa, Persephone and Eurydice to explore themes of memory, loss and trauma. ${ }^{23}$ For Butler, Eurydice's second death is a central, inevitable moment brought about by the act of looking and which, when rendered in the visual (and cinematic) arts, raises questions about the culpability of the viewing audience as much as of Orpheus himself:

Eurydice is, as we know, already lost, already gone, already dead, and yet, at the moment in which our gaze apprehends her, she is there, there for the instant in which she is there. And the gaze by which she is apprehended is the gaze through which she is banished. Our gaze pushes her back to death, since we are prohibited from looking, and we know that by looking, we will lose her. And we will not lose her for the first time, but we will lose her again, and it will be by virtue of our own gaze that she will be lost to us, and that she will, as a result, be apprehensible only as loss. ${ }^{24}$

In Portrait, Sciamma takes up this moment, giving it centralised space in the narrative and, in doing so, situates her work within a broader artistic tradition. Eurydice's story becomes not only the overarching narrative of the film, but also shapes its visual elements, most prominently in its evocation of Edward Poynter's 1862 painting in oils, from which Portrait appears to borrow the green and red clothing of its main figures as well as the rocky landscape behind. ${ }^{25}$ For Benjamin Eldon Stevens, the scene in which Héloïse reads from Metamorphoses 'is a microcosm of the film' in which its central thesis is aired. ${ }^{26}$ Here, the dark edges of the room fall away to the corners of the frame as, alone, lit only by candles and seemingly at the edge of the world, Marianne, Héloïse and Sophie set out the possible

Betsky, Queer Space, p. 34.

2 (Mallet 1780); for more on musical, specifically operatic, appropriations of the Orpheus and Eurydice narrative, see (Agnew 2008).

For more on Ettinger's treatment of Eurydice, see (Ettinger and Levinas 1997).

(Butler 2004).

(Poynter 1862)

(Stevens 2020). 
meanings of the tale. For Marianne, Orpheus makes the 'poet's choice', turning on purpose to condemn Eurydice and electing instead to retain only the memory of her. For Héloïse, it is Eurydice who calls out to Orpheus, choosing to die again rather than return with him to the surface and life. As Stevens describes, Sciamma gives this discourse around autonomy and consent meaningful space within the cinematic text:

Although the three women are all sitting at the same table, once the scene begins they are only shown separately: no two women are on screen at the same time. As the shot cuts to each several times in turn, emphasis falls on their individual perspectives even on shared experiences and feelings. Thus, this scene of reading aloud and debating an ancient story takes the form of a philosophical dialogue. ${ }^{27}$

Of course, perspective-who allows and who enacts vision, who invites and who reproduces it-is a contentious and highly present question within cinematic form, in which audiences are invited to retrace and share in the gaze of specific character(s). For Madeleine Saidenberg, the screen offers particular opportunity to explore queer gaze and invite viewers to peer into new spaces that might exist between a self-contained dramatic narrative and those consuming it. Saidenberg draws particular attention to the BBC's Gentleman Jack, in which the protagonist Anne Lister (Suranne Jones) regularly breaks the fourth wall (itself a Diderotian concept ${ }^{28}$ ) to gesture or speak directly to her television audience. The same space is briefly shared with another queer character, Anne Walker (Sophie Rundle), after she first acknowledges her own homosexual desires. ${ }^{29}$ In the context of Portrait's narrative, in which the production of the portrait and the processes by which it is made dominate, this central idea of vision and autonomy works to subvert the traditionally patriarchal artist-sitter binary. Before Marianne's arrival in Brittany, we are told, an anonymous male artist had failed to paint Héloïse's portrait for her Milanese fiancé thanks to his subject's refusal to be seen. Likewise, Marianne's early attempts, in which she merely observes Héloïse during the day before secretly attempting to replicate her in paint at night, are unsuccessful. Questions of bodily, sexual and artistic consent align. When Marianne asks of Héloïse's mother 'Why won't she be painted?' the answer is simply 'She refuses this marriage'. It is only once the nature of Marianne's commission is revealed and a mutual attraction acknowledged that Héloïse, like Eurydice inviting Orpheus' gaze, consents to sit for her. In Sciamma's words, 'there is no muse. The model and the artist are co-creators'. 30

For Diderot, writing in his Essai of 1765, the relationship between artist and sitter was problematic. Especially troubling were the static poses of the portrayed and the relative remoteness of the painter and the corresponding (in)accuracy of his observations:

[ ... ] all these movements coldly and ineptly imitated by some poor devil [ . . . ] who's paid to appear, undress, and let himself be manipulated by a professor three times a week, what do they have in common with postures and movements in nature. What does the man drawing water in the well in your courtyard have in common with another who, not pulling the same burden, awkwardly mimics this action[?] ${ }^{31}$

This dilemma has been consistently taken up by cinema, where scenes in which a sitter is appraised and replicated by an artist are consistently interested in the boundaries between life and art and the divergent ways in which they might be transgressed. For Susan Felleman, the proximity of the artist to real, fleshy bodies is paramount. The sitting onscreen, she argues, most often collapses 'artistic sensuality and human sexuality through scenes in which models become sexual objects, artistic compositions become sexual dramas,

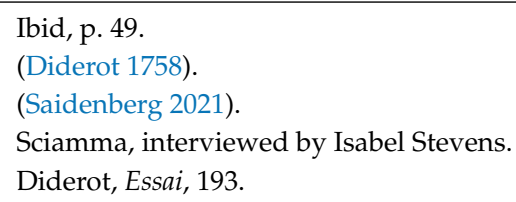


and visceral responses to artistic images slip into images of pornographic titillation'. ${ }^{32}$ Within this tradition, power most often resides with the artist, and is legitimised by the visual modalities of cinema through which the viewer is implicated. As Steven Jacobs has it, the painterly gaze is usually shown to govern by a 'kinetic cinematography [that] mimics the movement of [their] anxious eye' ${ }^{33}$ In Portrait, Sciamma offers a feminist revision of this trope, in which Marianne's eye is met with a ferocious reciprocity. As she positions Héloïse's limbs to a three-quarter pose and takes up a stick of charcoal to begin to mark the prepared canvas, the artist vocalises observations of her subject, noting in particular the mannerisms that manifest when Héloïse feels uncomfortable or afraid. In a compelling reversal of this one-way vision and the power that accompanies it, Héloïse invites Marianne to cross the room and stand next to her, instead looking back across at the unattended easel [Figure 1]. 'If you look at me, who do I look at?' she demands. In transgressing the threshold between artist and sitter, Marianne moves away from what Griselda Pollock has called 'an ideological relation to [the] world', one characterised by the technologies of perspective and classical training so emphatically rejected by Diderot and, in cinema, consistently encoded as patriarchal. ${ }^{34}$ The result is an onscreen articulation of a new two-way channel between representer and represented, in which the women's reciprocal gaze is made visible on film via a sequence of frames that give equal weight to the dialogic perspectives. ${ }^{35}$ Poised, or rather posed, on the edge of artistic creation, Héloïse directs Marianne's Orphic gaze to claim autonomy over both her visibility and her replication.

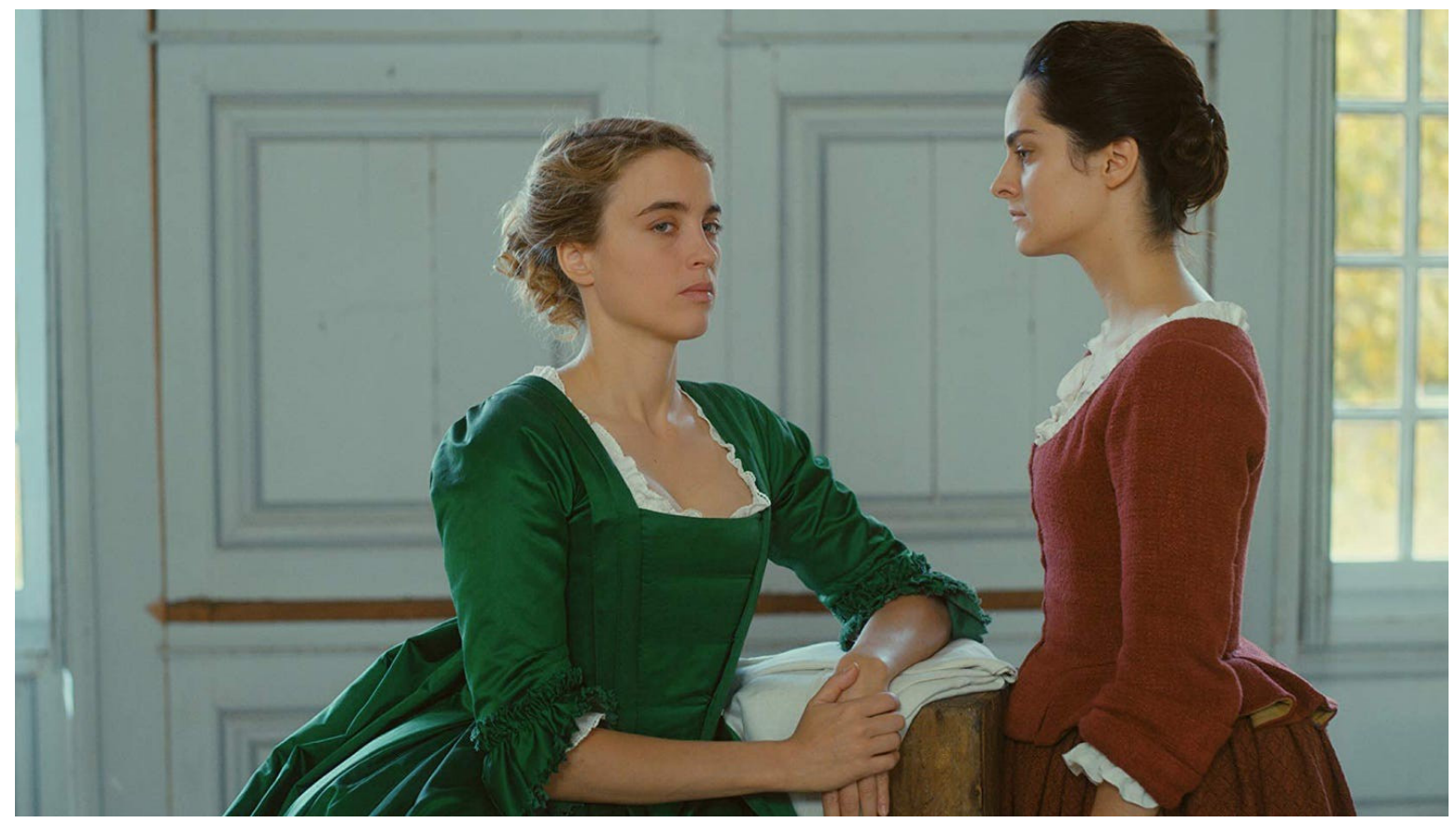

Figure 1. Marianne arranges Héloïse during the sitting in Portrait of a Lady on Fire, Sciamma (2019). Screenshot @ Lilies Films.

\section{Uncanny Visions and the Queer Canvas}

The processes and spaces of artmaking are notably messy in Portrait, and the vision of its practitioners open to corruption and compromise. Far from the precise indexical trace offered by later photography, the film presents painterly creation as a visceral and

32 Felleman, Art in the Cinematic Imagination, p. 142.

33 Jacobs, Framing Pictures, p. 55.

34 (Pollock 1999).

35 For the politics and limitations in complicating lines of vision in the heteronormative artist-sitter cinematic relationship, see (Vidal 2007). 
materially complex process, one necessarily transgressive of boundaries and ready to slip into the uncanny. Jacobs has suggested that the portrayal onscreen of artistic production hypostasises 'the confrontation between reality and image, flesh and oil, the three- and two-dimensional, and the living and the inanimate'. ${ }^{36}$ In Portrait, artworks are spatially, materially, emotionally and intellectually proximate to the embodied experiences of the characters. The blurring of living and replicated bodies becomes, at times, unsettling, and the artist's ability to control and contain her creations questionable. The large canvas on which Marianne paints stands just feet from the bed she sleeps in, where she and Héloïse make love and where Sophie recovers from an abortion. Within this space, artistic, bodily and elemental fluids combine. Marianne's hands are variously shown covered in paint and also in menstrual blood. After she and her canvases are submerged in the sea upon arrival at the island, both are warmed by fire; the nude body of the artist and her blank canvases submitting to the same transformation. Fire is the force around which the women gather in the heart of their domestic homosocial space, but it is not universally generative. When Marianne finds at night the ghostly remains of an earlier attempted portrait of Héloïse, painted before she arrived and subsequently rubbed out, she holds her candle too close and steps back in alarm when the flames catch the canvas and begin to tear eerily through the painted effigy.

Beyond its physical treatments, the painted canvas is encoded with a range of queer metres. Across the film text, artworks stand in for the complicated measurement of time itself, variously and sometime simultaneously representing memory, loss and the future. The production of the wedding portrait provides the overarching temporal structure, measuring out chronologically Marianne's time with Héloïse before her inevitable marriage, while smaller works (discussed below) seek to complicate and disrupt this linearity. Elsewhere, portraits speak to complicated genealogies beneath their explicitly heteronormative functions. Marianne's work, for example, might be intended for the delectation of Héloïse's future husband, but it also represents her own inheritance of her artist father's skill and, with it, her subversion of patriarchal structures within the eighteenth-century professional world beyond the cinematic frame. Sciamma similarly uses a portrait of Héloïse's mother, painted by Marianne's father a generation earlier, to underscore the uncanny in replicating the unconsenting female body on the marriage market. Of her own response to this work, Héloïse's mother describes to Marianne the moment she was confronted with herself reproduced: 'The portrait arrived here before me. When I first entered this room, I found myself facing my image hanging on the wall'.

Throughout, peripheral and diminutive works are used to explore the queer identities of Portrait's characters. Made using charcoal and pencils, rather than paint, these works are materially, spatially and visually set aside from the larger-scale formal and broadly heteronormative portraiture that leads the film's narrative. They are also produced in the more intimate and complex spaces of the world Sciamma creates, most notably the bed Marianne occupies and shares with Héloïse. On one occasion, Marianne sketches Héloïse's face as she flickers on the edge between sleep and waking. Later, once the women know they must part, Marianne pencils a miniature version of the larger portrait she has completed. A spatial and intellectual inversion of its original, the miniature is not intended as a futuristic gift to an invisible man but, rather, a talismanic record of their time and collaboration together. Such works exist in Portrait on the edges between past and present, and even life and death. When Héloïse's servant Sophie reveals that she is pregnant, the three women go together to a local medicine woman who performs an abortion. Marianne and Héloïse are positioned, like the cinematic viewer, as spectators to this procedure, in which Sophie lies on a bed, this time a space occupied by several children, while the abortionist goes about her work. Sciamma brings unusual warmth to the scene; a baby rolls across the bed to clasp Sophie's hand as her own pregnancy is terminated. The films asks us to bear witness to such histories. When Marianne is compelled to turn

36 Jacobs, Framing Pictures, p. 54. 
away, Héloïse tells her simply, 'look'. In reference to this episode, Sciamma cited Annie Ernaux's autobiographical novel L'Événement, as her inspiration. In it, Ernaux recounts an illegal abortion she had in 1963 and her regret that there are perhaps no 'great' artworks depicting such procedures hanging on the walls of the world's museums. ${ }^{37}$ In Portrait, the abortion scene is followed by one of physical and emotional recuperation. The three women are gathered in Marianne's room when Héloïse suggests they recreate the event in paint. Helping Sophie into position on a mattress on the floor, Héloïse assumes the pose of the abortionist while Marianne begins to sketch on a rough piece of wood. Taking place at night and lit only by the crackling fire with painterly chiaroscuro, the scene is largely silent as questions of women's autonomy in bodily and artistic reproduction, and the generative nature of cinema in replicating an image within an image, are brought to the fore.

Elsewhere, Sciamma deals with more literal reflections. Throughout Portrait, vision is redirected and refracted through mirrors. When Marianne sets about removing the ghostly white dust blankets draped over the contents of her room, she gasps in surprise on uncovering a large mirror and, framed within it, her own face. Sciamma is particularly interested in the self-reflective possibilities of the mirror and its potential to gesture to a world beyond the immediate and material, an alternative space which might contain not only different modes of seeing, but also of being. For Betsky, the mirror is resolutely queer and uncanny:

If queer space establishes itself at all, it surrounds us as a space that is often as invisible or as thin as the surface of a mirror. Mirror space is a strangely haunting space, one where the world comes back to us in a reversed manner. Everything is still there, in place but out of place. ${ }^{38}$

For Sciamma, the mirror provides a useful visual aid in enacting onscreen her feminist revisioning of art history. When Marianne sketches herself in the margins of Metamorphoses so that Héloïse might have an image to remember her by, she does so using a mirror. In the film's only instance of self-portraiture, she asks Héloïse to select a page at random-page twenty-eight-before placing the mirror over Héloïse's naked stomach and genitals as they lie on the bed together [Figure 2]. An overt gesture to Diego Velázquez's enduring seventeenth-century The Toilet of Venus, in which the embodied goddess lies with her back to the viewer and provocatively meets their eye via a mirror held up by Cupid,

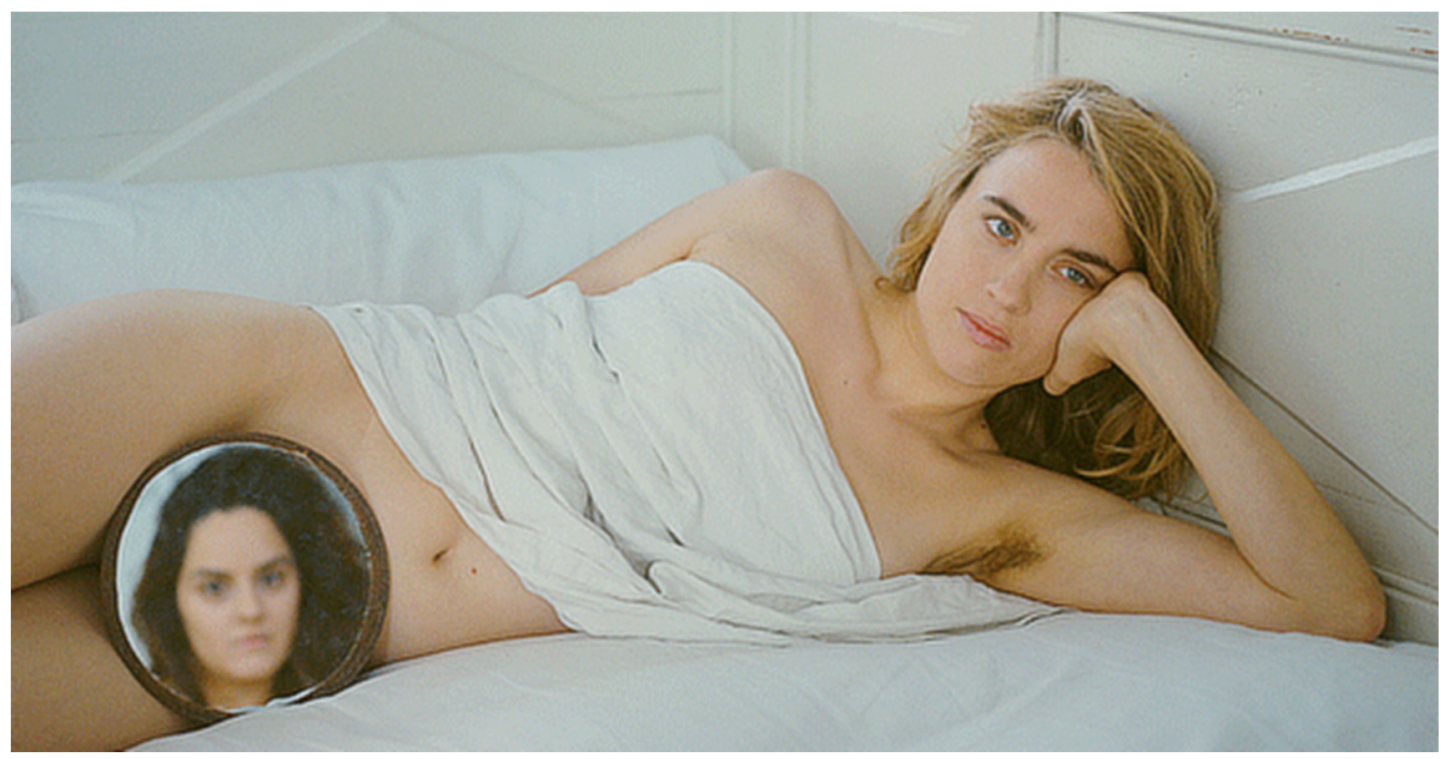

Figure 2. Marianne sketches a self-portrait using a mirror propped against Héloïse's stomach in Portrait of a Lady on Fire, Sciamma (2019). Screenshot (C) Lilies Films.

37 See Syme, 'Portrait of a Lady on Fire Is More Than A Manifesto on The Female Gaze'.

38 Betsky, Queer Space, p. 34. 
Sciamma explores the boundaries between intellectual and bodily experience in artmaking and what happens when the queer artist's gaze turns back on herself. ${ }^{39}$ Like Velázquez's Venus, Marianne is positioned with her back to the camera, although we see little of her naked body. Her vision connects momentarily with that of the cinematic viewer as she sets about reproducing the image in the mirror onto the page of the book. However, while Marianne sees her body reflected in the glass, the viewer sees only her face. Complicating Velázquez's original work, Sciamma places agency with the self-appraising nude-simultaneously artist and auto-subject. The scene also draws from a more recent and overtly queer visual history. In 1981, a self-portrait by photographer Armen Susan Ordjanian, in which she appears with a mirror resting against her raised legs and covering her genitals to instead reflect her face, featured in the premier issue of feminist magazine The Blatant Image [Figure 3]. ${ }^{40}$ In 2017, director Sebastián Lelio reproduced this work in the Spanish-language film Una mujer fantástica (A Fantastic Woman), in which its transgender protagonist similarly places a mirror over her genitals to instead reflect her self-assumed gender identity in its surface. ${ }^{41}$ In Portrait, the camera shifts repeatedly between the mirror and the work in pencil that Marianne is exactly on the page, presenting the small, private and peripheral space of the book as a receptive location for the rendering of her own image and, with it, her dual identity as both artist and queer woman.

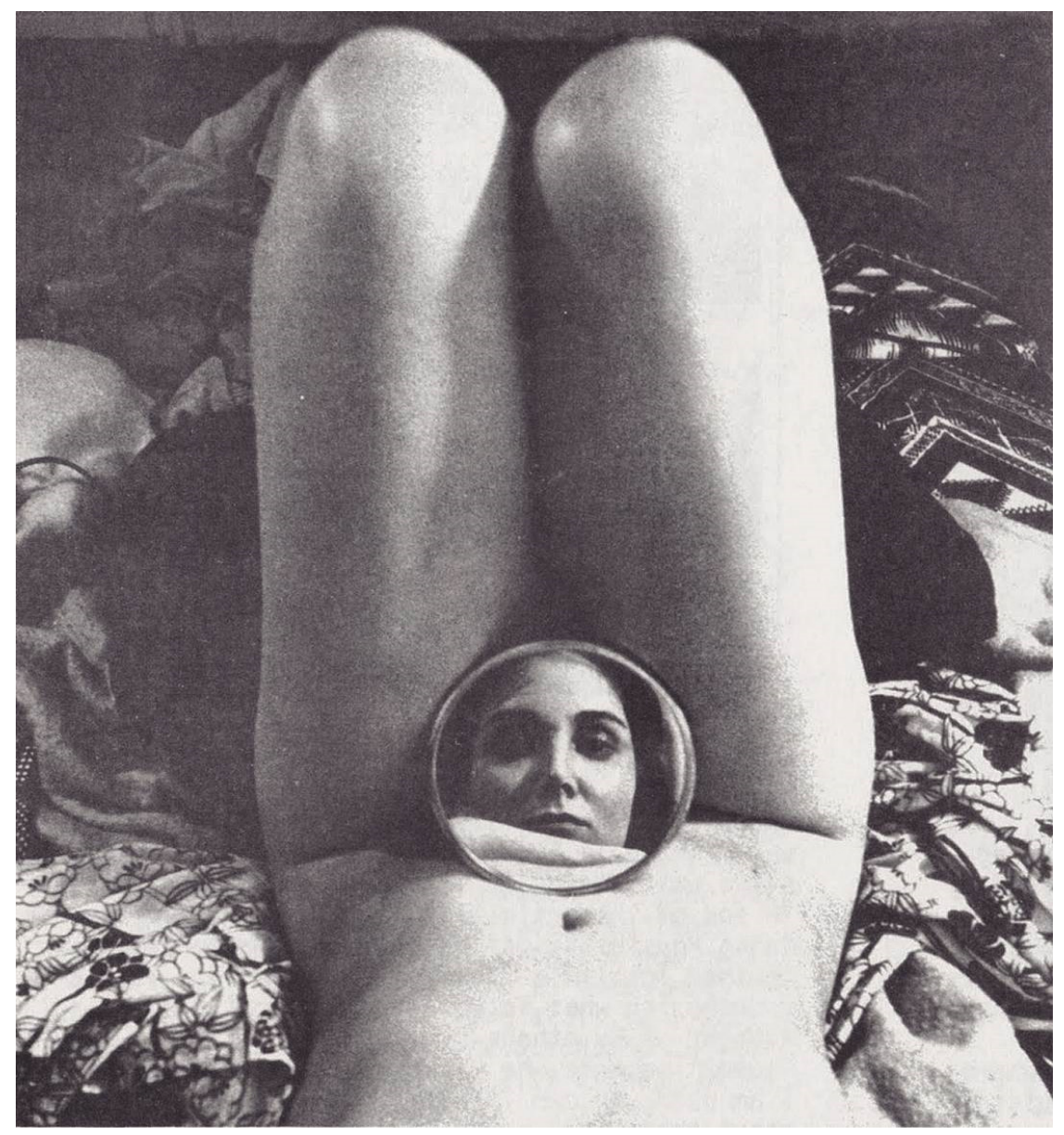

Figure 3. Self-Portrait, 1981. Photograph @1981 Armen Susan Ordjanian, All rights reserved.

39 Velázquez's Venus has historically been implicated in feminist discourse. In 1914, the suffragette Mary Richardson attacked the canvas with a meat cleaver in the National Gallery in London, slicing through the fleshy form of the goddess and, in doing so, referencing ongoing critical commentary on the distances between women's bodies and artistic representation.

40 (Ordjanian 1981).

41 (Lelio 2017). 
As Belén Vidal has argued, 'the reflexive styles of the European art film' speak to a self-awareness around the artificial construction of image and the possibilities inherent in blurring the lines between the artistic and cinematic frames. ${ }^{42}$ The most spectral image in Portrait comes when Marianne walks alone through the darkened interiors of the house at night and is met with a ghostly vision of Héloïse in a (historically anachronistic) white wedding dress [Figure 4]. The ghost is silent, each time framed in a doorway or corridor and lit with a theatrical artificiality, at odds with the muted palette and natural lighting of the rest of the film and frightening in its immediacy. Positioned centrally and turned fully to face Marianne, this figure is not that of the carefully posed painting she has created but something other-the ghost of a portrait not painted and a life, although kept peripheral by the queer lived experiences depicted onscreen, increasingly proximate. The threat of Héloïse's separation from Marianne and her impending nuptials are drawn, literally, from Marianne's imagination, in which the ghostly vision has crept beyond the two-dimensional canvas to encroach into the cinematic world. The expansion of the artist's work into the filmic aesthetic is not unique to Portrait. Jacobs notes, for example, how John Huston's Moulin Rouge (1952) borrows from the 'kind of hues' used by its protagonist ToulouseLautrec, Derek Jarman's Caravaggio (1986) makes use of the artist's dramatic chiaroscuro and Peter Webber's Girl With A Pearl Earring 'the colours and spatial dimensions' of Vermeer's oeuvre. ${ }^{43}$ In Portrait, this transgression makes visible onscreen the film's investment in the story of Eurydice and Orpheus. Like Eurydice, the ghostly form of Héloïse appears behind Marianne, compelling her to look and reminding her of the inevitable fate that awaits, posing the question of when the real-life moment to part arrives, who will consent to it and who resist? The prophetic vision is made reality in the final act of the film, when Héloïse, mid-wedding dress fitting, chases after Marianne, who is leaving following the completion of the portrait. The scene takes place in the liminal, transitory space of the hallway, with Marianne paused on the threshold of the door and Héloïse stopped on the stairs. Like the Eurydice she imagines when reading Ovid, Héloïse calls out for Marianne to 'turn around'. The artist does so, acknowledging Héloïse in her wedding clothes and so cementing their respective, and separate, fates. The moment recalls Betsky's definition of queer space as an often performatively 'ironic or rhetorical twist' on a recognisable order. Here, the women knowingly enact (and queer) the classical form and rhythms of Ovid's original tale in a conscious reversal of Diderot's prescribed life-art dynamic.

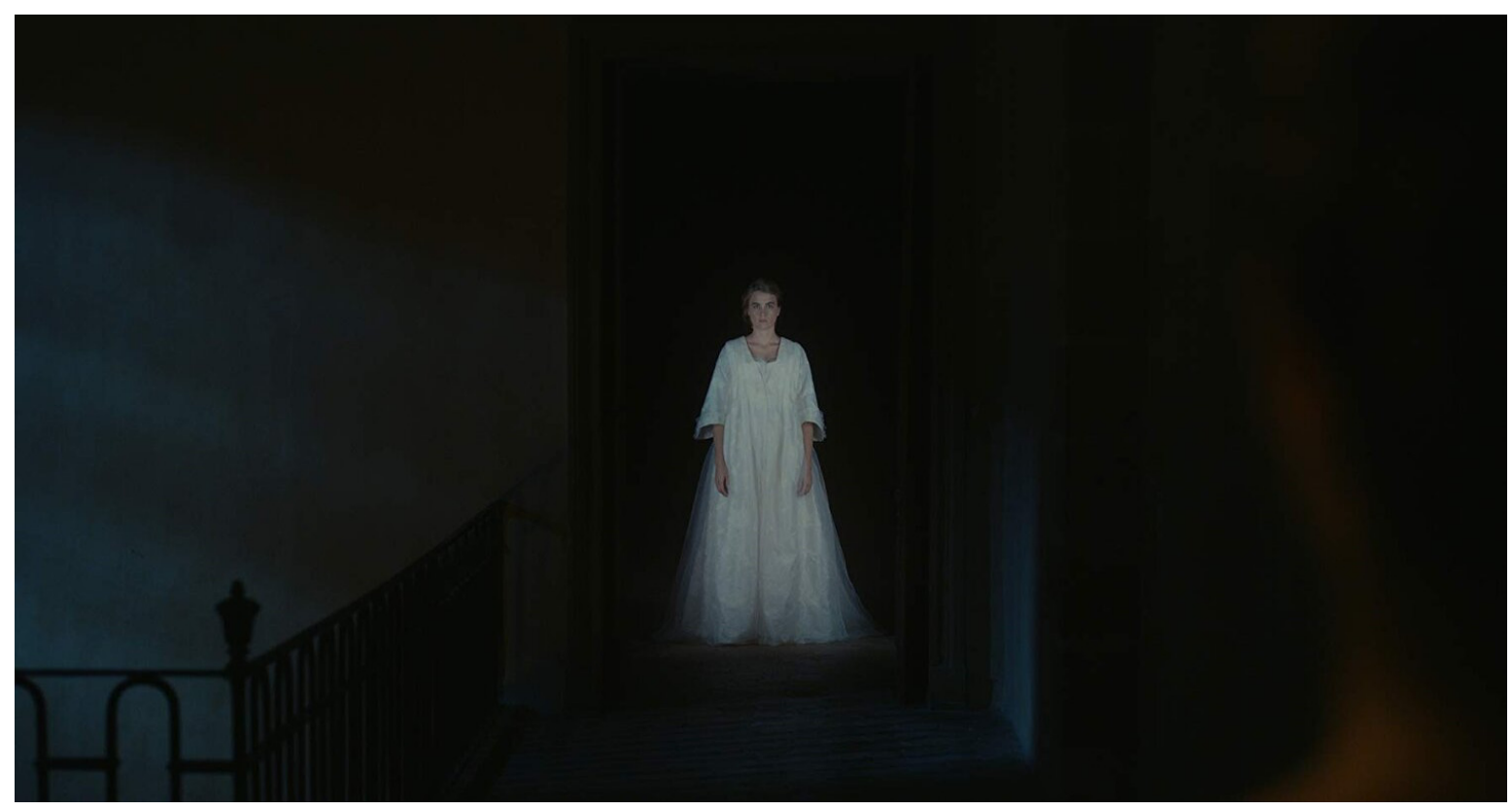

Figure 4. The ghost of Héloïse in her wedding clothes in Portrait of a Lady on Fire, Sciamma (2019). Screenshot (C Lilies Films.

42 Vidal, 'Feminist historiographies and the woman artist's biopic', p. 70.

$43 \quad$ Ibid, pp. 52-53. 


\section{Conclusions}

The final scenes of Portrait take place away from the isolated Brittany island in which the film's main action occurs. Instead, the viewer finds Marianne, years later, in the busy salon of Paris' Royal Academy. Onlookers and critics alike bustle around, recalling perhaps Diderot's own description of attending the hang upon the request of his friend Friedrich Melchior Grimm, later published in the periodical La Correspondance littéraire, philosophique et critique:

It's the task you set me that fixed my eyes on the canvas and made me circle around the marble. I gave my impressions time to coalesce and settle in. I opened my soul to the effects, I allowed them to penetrate through me. ${ }^{44}$

Marianne is shown moving through this space with the traditional salon booklet, Explication des peintures, sculptures, et autres ouvrages, de messieurs de l'Académie royale, in her hands, a decision that serves to situate Portrait firmly within eighteenth-century Academy and the textual and dialogic cultures that sprang from it. ${ }^{45}$ However, she is not merely a spectator. Her own work, a painting set within the recognisably rocky landscape of the Brittany coast and depicting the moment Orpheus looks at Eurydice and she is dragged to Hades, becomes the subject of scrutiny when a Diderotian critic appears beside her to appraise it. This painting is, however, not the enduring image of the film. While in attendance, Marianne discovers a new portrait of Héloïse, accompanied now by her child and painted by an unknown artist. Standing before it, her eye is drawn to a book depicted in Héloïse's lap, the subject's fingers suggestively peeling back the corners of its pages. Revealed beneath is the number twenty-eight, a reference to the page on which Marianne sketched her self-portrait; a work that, the cinematic audience might surmise, Héloïse has secretly treasured and which is referenced here as a discrete communique to her lost love. The film returns again to its recurring interest in images within the cinematic frame. The painting, itself portrayed within the boundaries of the film, contains inside it another, queer artwork to which only Héloïse, Marianne and the filmic viewer are privy, hidden within the heteronormative and patriarchal image of a progenitive wife. Rather than follow historical painterly conventions-such as an open bird cage, commonly used to signal a loss of virginity after marriage-Sciamma described how, in this final artwork, the film looks to create a new visual coding, one that might have real-world implications beyond the cinematic in its demarcation of queer space:

[T]here's mystery also because this number didn't mean anything before the film, but it will suddenly: it's that language that you now speak and a world you become part of. It belongs to the film but will live beyond the film. I want people to get 'page 28 ' tattoos. I wonder if anyone will hide notes at that page. I know that now when I want to hide something in a book, I'll put it on page $28 .{ }^{46}$

For Laura Mulvey, the advent of digital technologies and, with it, viewers' ability to fragment, re-watch, skip over and select favourite scenes from a film has led to a 'heightened relation to the human body, particularly that of the star' ${ }^{47}$ Now, to borrow Mulvey's term, the 'possessive spectator' interacts with and consumes cinema in new ways that 'bridge between the irretrievable spectacle and the individual's imagination' ${ }^{48}$ ' $[\mathrm{F}] \mathrm{rom}$ a theoretical point of view', Mulvey argues, 'this new stillness exaggerates the star's iconic status' ${ }^{49}$ Here, I would like to suggest, Sciamma harnesses, and queers, this emerging need of the viewer to possess the 'ephemeral experience of kinematics' through photographic stills, posters and other promotional or fan-made visuals. As Patricia MacCormack similarly

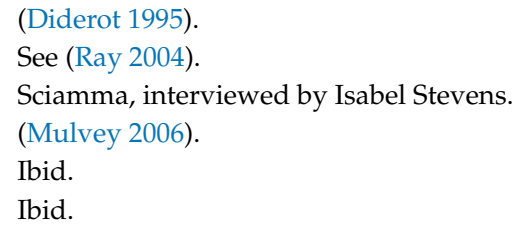


has it, '[w]e want all cinematic images because we want to launch the becomings available through this most special of relations' ${ }^{50}$ By placing Marianne's artwork so prominently onscreen, Sciamma presents her audience with ready-made and possessable imagery, the creation of which we are privy to. Far from a filmmaker/viewer binary, in which the dialogue is usually one-sided, Portrait offers its viewers a synthetic community, one built around and highly conscious of female creativity and the processes of making, be it eighteenth-century art or twenty-first century film. Extending the text's visual codes beyond the bounds of the screen and into real life, Sciamma offers us not only access to Portrait's most intimate moments, but also participation in them.

The film, then, is not only interested in imagining historical queer lives, but sets out an argument for cinema as the natural inheritor in a long technological, aesthetic and narrative genealogy that encompasses, and goes beyond, eighteenth-century artmaking to envision, and recentre, queerness in visual, spatial and temporal terms. From its reception of Ovid's Metamorphoses to its engagement with the ideas espoused by historical critical texts, the film looks to recentre embodied sapphic experience alongside, and in dialogue with, feminist art histories. In particular, it seeks to centralise such histories onscreen by making visible the marginal and diminutive spaces of eighteenth-century art as a physical record of queer lives. Self-conscious of its own cinematic form throughout, the film's concern with the processes and spaces by which queer women make art is twofold and extends beyond Marianne's canvas to Sciamma's screen. It is also highly aware of its audience and cinema's potential to direct and reshape their experience. When we see the final portrait of Héloïse in the salon, we recognise its queerness because we too have spent time in the peripheral spaces that mark the relationship between the two women, space we might, Sciamma suggests, carry with us into the material world.

Funding: This research received no external funding.

Acknowledgments: I am grateful to Gemma Tidman and Madeleine Saidenberg, both of whom read and commented on earlier versions of this work, and to the two anonymous reviewers and Special Issue editor Declan Kavanagh for their generous feedback.

Conflicts of Interest: The author declares no conflict of interest.

\section{References}

Agnew, Vanessa. 2008. Enlightenment Orpheus: The Power of Music in Other Worlds. Oxford: Oxford University Press.

Berns, Fernando G. Pagnoni. 2017. Water and Queer Intimacy. In Space and Subjectivity in Contemporary Brazilian Cinema. Edited by Antonio Marcio da Silva and Mairana Cunha. New York: Springer International Publishing, pp. 185-200.

Betsky, Aaron. 1997. Queer Space: Architecture and Same-Sex Desire. New York: William Morrow \& Co., p. 18.

Butler, Judith. 2004. Bracha's Eurydice. Theory, Culture \& Society 21: 95.

Castle, Terry. 1993. The Apparitional Lesbian: Female Homosexuality and Modern Culture. New York: Columbia University Press, p. 2.

Diderot, Denis. 1758. Discours Sur La Poésie Dramatique. Amsterdam: Unknown Publisher.

Diderot, Denis. 1765. The Salon of 1765. In Diderot on Art. Translated by John Goodman. New Haven: Yale University Press, p. 3.

Diderot, Denis. 1995. Essai sur la peinture. In Diderot on Art. Translated by John Goodman. New Haven: Yale University Press, vol. I, p. 194.

Donoghue, Emma. 1995. Passions between Women: British Lesbian Culture 1668-1801. New York: HarperCollins, p. 184, quoted in Klein, 'Dildos and Material Sapphism', p. 398.

Ettinger, Bracha Lichtenberg, and Emmanuel Levinas. 1997. Que dirait Eurydice? Emmanuel Levinas en conversation avec Bracha Lichtenberg-Ettinger. Paris: BLE Atelier.

Felleman, Susan. 2006. Art in the Cinematic Imagination. Austin: University of Texas Press.

Haggerty, George. 2006. Queering Horace Walpole. Studies in English Literature, 1500-1900 46: 543-61. [CrossRef]

Halberstam, J. Jack. 2005. In a Queer Time and Place: Transgender Bodies, Subcultural Lives. New York: New York University Press, pp. 13, 20.

Handyside, Fiona. 2014. Cinema at the Shore: The Beach in French Film. Oxford: Peter Lang.

Jacobs, Steven. 2012. Framing Pictures: Film and the Visual Arts. Edinburgh: Edinburgh University Press, pp. 41-42.

Jones, Amelia. 2012. Seeing Differently: A History and Theory of Identification and the Visual Arts. London: Routledge.

50 MacCormack, Cinesexuality, p. 1. 
Klein, Ula Lukszo. 2018. Fashionable Failures: Ghosting Female Desires on the Big Screen. In The Cinematic Eighteenth Century: History, Culture, and Adaptation. Edited by Srividhya Swaminathan and Steven W. Thomas. Abingdon: Routledge, p. 14.

Klein, Ula Lukszo. 2019. Dildos and Material Sapphism in the Eighteenth Century. Eighteenth-Century Fiction 31: 412. [CrossRef]

Laffly, Tomris. 2020. Portrait of a Lady on Fire Cinematographer, Costume Designer on the 'Painterly' 18th-Century Look. Variety. 65. Available online: https:/ /variety.com/2020/artisans/production/portrait-of-a-lady-on-fire-costume-designer-cinematographer1203508292/\#: \{\}:text=She\%20also\%20relied\%20on\%20rich, authenticity\%20and\%20modern\%2Dday\%20sensibilities (accessed on 29 April 2021).

Lelio, Sebastián. 2017. Una mujer fantástica. Directed by Sebastián Lelio. Malaga: Fabula Komplizen Film.

MacCormack, Patricia. 2008. Cinesexuality. Aldershot: Ashgate, p. 31.

Mallet, David. 1780. Eurydice: A Tragedy. As It Is Acted at the Theatres-Royal in Drury-Lane and Covent-Garden. By Mr. Mallet. London: Printed for Harrison and Co.

Mulvey, Laura. 1975. Visual Pleasure and Narrative Cinema. Screen 16: 8-9. [CrossRef]

Mulvey, Laura. 2006. Death $24 x$ a Second: Stillness and the Moving Image. London: Reaktion Books, p. 161.

Ordjanian, Armen Susan. 1981. Self-Portrait. In The Blatant Image: A Magazine of Feminist Photography. Sunny Valley: Blatant Image.

Pollock, Griselda. 1999. Differencing the Canon: Feminist Desire and the Writing of Art's Histories. London and New York: Routledge, pp. 97-127.

Poynter, Edward John. 1862. Orpheus and Eurydice. sold at Christie's in December 2020. Available online: https://www.christies.com/ en/lot/lot-6290737 (accessed on 13 January 2021).

Pullen, Christopher. 2018. Queer Male Bodies and the Cinematic Liminal Beach. Film International 16: 27-36. [CrossRef]

Ray, William. 2004. Talking about Art: The French Royal Academy Salons and the Formation of the Discursive Citizen. EighteenthCentury Studies 37: 527-52. [CrossRef]

Saidenberg, Madeleine. 2021. ‘Do Ladies Do That?' in 2020: Imagining New Queer Histories through Period Absurdism. Paper presented at British Society for Eighteenth-Century Studies Annual Conference, January 5-6.

Sciamma, Céline. 2019. Portrait de la Jeune Fille en Feu. Paris: Lilies Films.

Sciamma, Céline. 2020. No man's land: Céline Sciamma on Portrait of a Lady on Fire. Sight \& Sound. Available online: https://www2 .bfi.org.uk/news-opinion/sight-sound-magazine/interviews/portrait-lady-fire-celine-sciamma-female-sex-art-solidarity (accessed on 18 December 2020).

Stevens, Benjamin Eldon. 2020. "Not the Lover's Choice, but the Poet's": Classical Receptions in Portrait of a Lady on Fire. Frontière.s: Revue d'Archéologie, Histoire E Histoire de l'Art 2: 50.

Vidal, Belén. 2007. Feminist historiographies and the woman artist's biopic: The case of Artemisia'. Screen 48: 69-90. [CrossRef] 